\title{
A TEMPORALIDADE MESSIÂNICA DE TRAMA (ANTONIO DIAS, 1977)
}

Gustavo Motta

\section{RESUMO}

Trama, de Antonio Dias, é uma coleção de xilogravuras, exposta, aludindo à série The Illustration of Art (1972-77), como um painel semi-retangular que se apresenta em lapso. As estampas expõem estruturas gráficas retomadas às pinturas "diagramadas" realizadas pelo artista entre 1968-71. Em cada estampa há diferentes proposições escritas, formando uma série de "plantas baixas", propositoras de "monumentos" geométricos - calcados na participatividade da arte ambiental de $\mathrm{H}$. Oiticica, e... impossíveis de serem realizados. Proposições de ação futura ou descrições do espaço experimentado? Ao contrapor materiais históricos do debate artístico brasileiro (fragmentos da geometria desenvolvimentista e da "participação do espectador" da resistência cultural de 1964-69), Trama opera uma aglutinação de tempo histórico, que implica uma nova temporalidade recheada daquele "tempo-deagora" descrito por W.Benjamin: o tempo aberto para as possibilidades infinitas que promete a revolução social.

Palavras Chave

Antonio Dias, Hélio Oiticica, participação do espectador, Walter Benjamin.

\section{Abstract}

The collection of woodcuts that compose Antonio Dias' Trama is exposed as a semirectangular panel, that alludes to The Illustration of Art (1972-77) series. The prints expose some graphic structures taken from his "diagram-paintings" series, made between 1968-71. In each print there is a different written proposition, forming several "floorplans", that propose to erect a series of impossible geometric "monuments" - related, in a way, to the participatory dimension of H.Oiticica's "environmental art". Are those prints proposals for future action or descriptions of an experienced place? By interposing historical materials from the Brazilian artistic 
debate (pieces of geometry from the national-developmentalist period of the 50's and the "participation of the spectator" from the cultural resistance of the 60's), Trama operates an assemblage of historical time, which implies a new temporality - filled with that Jetztzeit described by Walter Benjamin: the open temporality of infinite possibilities promised by the social revolution.

\section{Key words}

Antonio Dias, Hélio Oiticica, participation of the spectator, Walter Benjamin.

"Rastro e aura. O rastro é a aparição de uma proximidade, por mais longínquo esteja aquilo que o deixou. A aura é a aparição de algo longínquo, por mais próximo esteja daquilo que a evoca. No rastro, apoderamo-nos da coisa; na aura, ela se apodera de nós." 1

Walter Benjamin, Passagens (M 16a, 4)

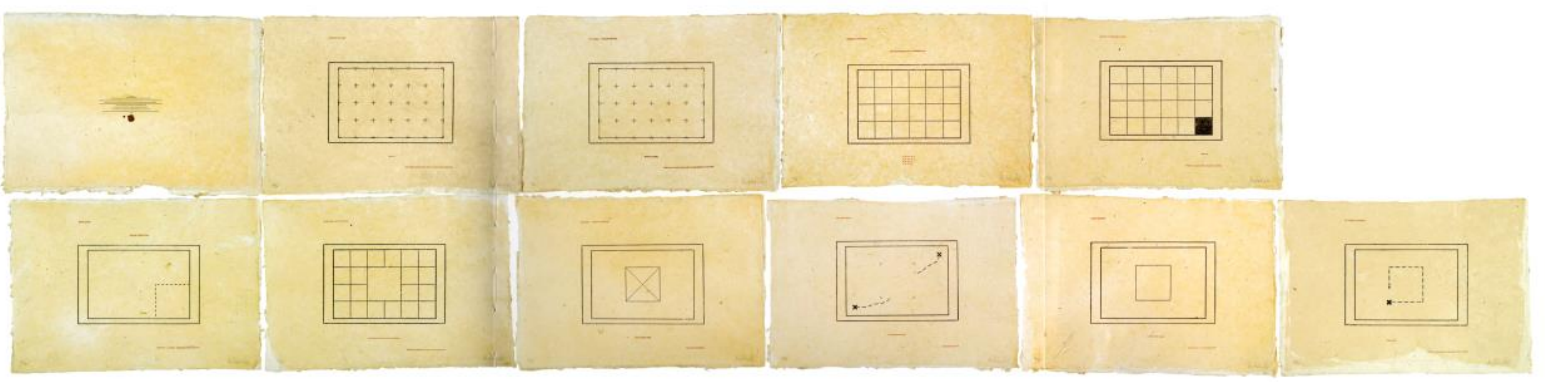

Antonio Dias, Trama, 1969/1977, álbum com dez xilogravuras sobre papel artesanal nepalês, 56 × $82 \mathrm{~cm}$ cada, MAC-Niterói.

Arte moderna brasileira: geometria, participação do espectador e imagem

\footnotetext{
${ }^{1}$ Benjamin, Walter, Passagens. Org. da edição brasileira Willi Bolle. Trad. Irene Aron e Cleonice Mourão. Editora UFMG, Belo Horizonte, 2007, pág. 490.
} 
Em vista da inflexão política da modernização no Brasil e com o golpe militar, o debate artístico brasileiro realizou, entre 1964 e 1969, uma crítica da obra-de-arte contemplativa, entendida como objeto portador de aura. Enquanto, no âmbito político, o golpe militar de 1964 fechou as portas da democratização, a discussão artística então, com a Nova Figuração (1963-1967), negou criticamente o paradigma estético da geometria, ligado ao ideário planejador do nacional-desenvolvimentismo - com os movimentos Concreto (a partir de 1953-1955) e Neoconcreto (a partir de 1957).

A Nova Figuração negava o dado aparente do desenvolvimento da arte moderna no Brasil (a geometria), mas dava seqüência ao conteúdo histórico da "participação do espectador", que havia surgido no neoconcretismo.

\section{O programa ambiental e a participação do espectador}

Em 1966 Hélio Oiticica, ligado anteriormente ao neoconcretismo, formulou seu programa ambiental. ${ }^{2}$ "Arte ambiental" é a proposição (do artista) de participação (do público), de acordo com a lição de W.Benjamin em O autor como produtor, segundo a qual o espectador deve se converter num colaborador. ${ }^{3}$ Central nesta concepção é a categoria de objeto - agora um sinal dentro do ambiente -, que passa a ser um ativador de ações e não uma "obra-de-arte". O debate artístico brasileiro havia operado uma espécie de neutralização da dimensão aurática do objeto.

"O interesse se volta para a ação no ambiente, dentro do qual os objetos
existem como sinais, mas não mais simplesmente como 'obras': esse caráter
de sinal vai sendo absorvido e transformado também no decorrer das
experiências, pois é agora a ação ou um exercício para um comportamento

\footnotetext{
2 Oiticica, Hélio, "Programa Ambiental". In: idem, Hélio Oiticica - Catálogo de exposição (Witte de With, Rotterdam, 22.02-26.04.1992; Galerie Nationale du Jeu de Paume, Paris, 08.06-23.08.1992; Fundació Antoni Tàpies, Barcelona, 01.10-06.12.1992; Fundação Calouste Gulbenkian, Lisboa, 20.01-20.03.1993; Walker Art Center, Minneapolis, 31.10.1993-20.02.1994; Centro de Arte Hélio Oiticica, Rio de Janeiro, 30.09.199630.01.1997), org. Guy Brett, Catherine David, Chris Dercon, Luciano Figueiredo e Lygia Pape, Rio de Janeiro, Projeto Hélio Oiticica, 1997 (doravante Catálogo H.O.), pp. 103-105.

${ }^{3}$ Benjamin, Walter, El autor como productor, trad. y pres. Bolívar Echeverría, Ciudad de Mexico, Editorial Itaca, 2004, pp. 49-50.
} 
que passa a importar. A obra de arte (...) é uma questão superada. [...] $\mathrm{O}$ artista é propositor de atividades criadoras: o objeto é a descoberta do mundo a cada instante". ${ }^{4}$

\section{Ruptura}

No entanto, em 1969, com o Al-5, veio a revanche do regime militar. Assim, aquele "instante" de superação do objeto que entreviu Oiticica foi bloqueado. Dentro do país, se assistiu, no início da década de 1970, o "milagre brasileiro", que gerou um "boom" no mercado artístico. ${ }^{5}$ Organizava-se a cena que operaria, ao final da década, a reconstituição fetichista do objeto no circuito artístico nacional, e, a retomada de seu caráter aurático. ${ }^{6}$ Seria possível resistir, tensionando o novo contexto que se abria?

Oiticica já havia notado uma tensão interna na obra de Antonio Dias, dentro da qual a vocação para a inserção no ambiente seria definida, segundo Oiticica: por uma "luta entre o quadro como repositório experimental e a concretização num outro espaço (que seria fatalmente ambiental) dessas experiências". ${ }^{7}$ Dessa luta interna do quadro, resulta o corte fragmentário das obras de Dias, que desloca a ênfase no objeto para uma ênfase no processo de abstração do objeto, sua negação.

Mediante o uso repetido de figuras (clichês tomados da pop art) e módulos geométricos, (tomados da minimal art) e a ênfase na reprodutibilidade, o objeto surge ao olhar como abstrato ou conceitual - formulação de um problema para a reflexão e a crítica.

\footnotetext{
${ }^{4}$ Oiticica, Hélio, “Instâncias do Problema do Objeto". In: Revista GAM, no 15, 1968, Rio de Janeiro, Fevereiro 1968, pp. 27-28. Grifos meus.

${ }^{5}$ Ver, para um documento de época: Zílio, Carlos; Resende, José; Brito, Ronaldo; Caldas, Waltércio, “O boom, o pós-boom e o dis-boom". Em: Basbaum, Ricardo (org.), Arte Contemporânea B rasileira. Rios Ambiciosos, Rio de Janeiro, 2001, pp. 179-196.

${ }^{6}$ Cf. Martins, Luiz Renato, "Formação e Desmanche de um Sistema Visual Brasileiro Moderno", in Margem Esquerda - ensaios marxistas, n. 9, São Paulo, Boitempo, 2007, p. 164-165.

${ }^{7}$ Oiticica, Hélio, "Vivência do Morro do Quieto" (1966). In: Basualdo, Carlos (org.), Tropicália: uma revolução na cultura brasileira. Cosacnaify, São Paulo, 2007, p. p. 218.
} 
Trama, de A. Dias, é uma operação crítica realizada "no instante do perigo", em meio às transformações da arte brasileira, nos anos 1970, como uma espécie de resumo da história da arte recente no país, composta apenas de "citações" visuais e escritas, intercambiáveis entre si. ${ }^{8}$

\section{Analítica do tempo: projeto, biografia e monumento}

Nas pinturas "diagramadas" produzidas a partir de 1968, surgem duas referências temporais: as formas

1) da "biografia" (a descrição ou narração de algo acontecido), como em The Lin Piao Biography (1968), AlphaOmega Biography (1968), Incomplete Biography (1968);

2) do "projeto" (a proposição de algo a se realizar), como em Project for an Artistic Attitude (1970), Project for “The Body” (1970), Project for a People’s Flag (1970).

Há, ainda, uma terceira referência, relativa à dimensão espacial. Mas não se trata de uma dimensão espacial "pura" (geométrica), e sim estruturalmente ligada à concentração de temporalidade: a forma do "monumento" como em The Unfinished Monument (1969), Chinese Monument (1970), e Monument to the Memory (1970). Os "fatos" registrados em imagens nas obras anteriores (até 1968), cedem lugar ao procedimento de diagramação do quadro, no qual se pode dizer que falta a imagem.

\section{A trilha de Trama}

Em 1969 Antonio Dias começava a projetar um livro, em diálogo direto com Hélio Oiticica, que deveria chamar-se Projectbook - 10 plans for open projects. ${ }^{9} \mathrm{O}$ trabalho restará

\footnotetext{
${ }^{8}$ Reproduções digitais das obras de A.Dias citadas podem ser encontradas na seção "Obras" do site oficial do artista: www.antoniodias.com/.

${ }^{9}$ Ver Oiticica, Hélio / Dias, Antonio, “Projectbook - 10 plans for open projects”. Fac-símile digital de documentos originais, a partir do arquivo online Programa Hélio Oiticica, parceria do Projeto Hélio Oiticica e Itaú Cultural, desenvolvido sob coordenação de Lisete Lagnado.
} (http://www.itaucultural.org.br/aplicexternas/enciclopedia/ho/home/index.cfm) 
inacabado, mas sua lógica será reutilizada, de maneira fragmentária, em Trama (1977). ${ }^{10}$ Em sua versão final, Trama não será um livro, mas uma coleção de 11 gravuras em madeira, expostas num painel como The Illustration of Art/ Dazibao/ The Shape of Power (1972). Seu modo de exposição também alude à série de Modelos de The Illustration of Art (1972-77), como um painel retangular que não se completa.

A exposição remete a outras obras, obrigando o espectador a uma visada retrospectiva. A remissão também expõe outras obras de Dias: as palavras e os sinais gráficos que provêm das pinturas "diagramadas" de 1968-70 e acrescidas de intervenções escritas ou gráficas. Junto à retomada do aparato gráfico das pinturas, aparecem diferentes proposições escritas que formam, com os elementos visuais, uma série de planos, cartografias ou plantas arquitetônicas que propõem "monumentos" geométricos (como nas pranchas "MONUMENTO À MEMÓRIA", "SEMPRE-VERDE / MONUMENTO À AGRICULTURA" e "MONUMENTO CHINÊS"), calcados conceitualmente na lógica participativa e "ativadora de experiências", da arte ambiental de Hélio Oiticica.

\section{Geometria...e montagem}

A dimensão gráfico-visual da obra é tomada de empréstimo à minimal art americana. ${ }^{11}$ Mas não se trata de um empréstimo puro. Mediante a montagem, Dias carrega a geometria - idealmente "pura" e auto-referente - de dois conteúdos (histórico-sociais) distintos. De um lado, o caráter modular-industrial das formas, da minimal. De outro lado, o caráter pedagógico-visual das composições geométricas do Concretismo brasileiro dos anos 1950. O que se opera, numa camada superficial, é um jogo lúdico-pedagógico de reorganização e recomposição das formas. Mas, associa, pela sobreposição de conteúdos históricos das formas, Concretismo brasileiro e minimal art americana (o passado desenvolvimentista nacional às formas industriais do mainstream artístico internacional).

Assim, Trama opera um juízo sobre a sucessão de estilos dentro da disciplina "história da arte" - de acordo com Susan Buck-Morss: "[...] quando a novidade se tornou um

\footnotetext{
${ }^{10}$ (PHO 0306/69) OITICICA, Hélio, “Special for ANTONIO DIAS' Projectbook”. Fac-símile digital de documentos originais, a partir do arquivo online Programa Hélio Oiticica, op. cit.

${ }^{11}$ Ver a série “L Beams” (1965) do minimalista americano Robert Morris (1931-).
} 
fetiche, a própria história se torna a manifestação da forma-mercadoria". ${ }^{2}$ (Em Trama, a história da arte serve de modelo à concepção de história, modelo que deve ser submetido à crítica).

Antonio Dias busca a desnaturalização do objeto e do discurso artístico. Trata-se da exposição da existência social do objeto artístico - existência histórica e não ontológica. Essa exposição da existência social da obra de arte se opõe à concepção cíclica e fetichista de história que rege a temporalidade da forma-mercadoria.

\section{Arbítrio e lógica}

Aqui, a escolha de signos lógico-abstratos não é idealista. Dias toma signos da abstração lógica e demonstra, no processo da redisposição, a lógica que lhes é subjacente (a da abstração), a lógica do intercâmbio onde cada elemento geométrico se abstrai no outro. Mais: ao intercambiar signos e matérias tão diferentes quanto são pinturas, instalações e objetos na lógica abstrata do desenho - do design - aparece uma cisão interna de tempo: não se pode saber se estes signos são 1) projetos (ideação de uma materialidade futura), ou se funcionam como 2) descrições analíticas, advindas da experiência do espaço (como mapas), funcionando como experiência do instante. É, portanto unidade contraditória cindida em dois momentos: o do projeto e o da experiência. $O$ uso da matéria "abstrata" e "lógica" é materialista e histórica, visto que não são formas geométricas "puras", mas, como vimos, matérias-primas visuais do debate da arte brasileira dos anos 50 e 60.

Visualmente, as palavras escritas nas estampas também funcionam como elementos gráficos, submetidas a uma mesma lógica de diagramação. Os conteúdos semânticos das palavras figuram como "sinais" da participação do espectador (vindos da resistência cultural de esquerda dos anos 1964-69). As sentenças aparecem deslocadas ou arrancadas de um texto maior, explicitando o jogo de arbitrariedade. As palavras funcionam como falsas legendas, ou, ao contrário, os desenhos é que são falsas ilustrações.

\footnotetext{
${ }^{12}$ Buck-Morss, Susan, Dialética do Olhar - Walter Benjamin e o projeto das Passagens, trad. Ana Andrade, Ed. UFMG, Belo Horizonte, 2002, p. 113.
} 


\title{
Rastros
}

Rastros: Uma gravura da série alude diretamente à intervenção ambiental Do it Yourself: Freedom Territory (1969).$^{13}$ O caráter propositivo e ambiental é sublinhado no texto do projeto original de Trama (Project-book - 10 plans for open projects, 1969). Diz o texto:

\begin{abstract}
"Faça você mesmo: Território Liberdade / uma estrutura básica e aberta, que funciona apenas a partir do momento em que alguém utiliza o espaço declarado livre para colocar uma ação, seja mental, física ou visual. É importante que a pessoa adote uma postura completamente nãocondicionada antes de penetrar o território-estrutura. Sem dimensões préestabelecidas: a ser feito em qualquer escala." ${ }^{14}$
\end{abstract}

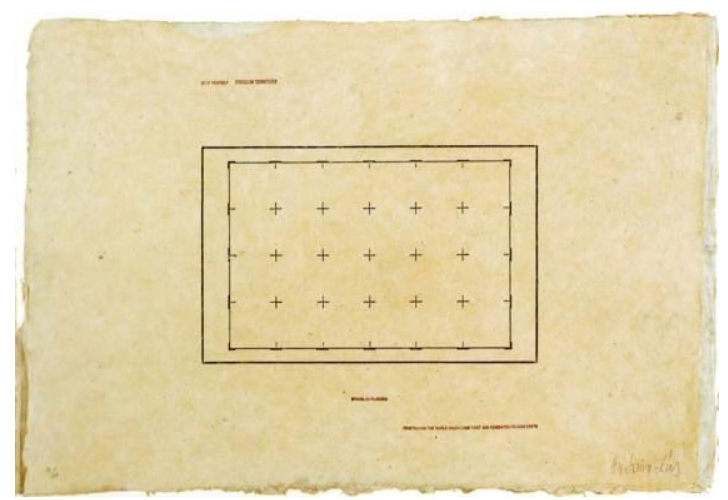

Antonio Dias, Trama (prancha 3 - Do it yourself), 1969/1977, álbum com dez xilogravuras sobre papel artesanal nepalês, $56 \times 82 \mathrm{~cm}$ cada, MAC-Niterói.

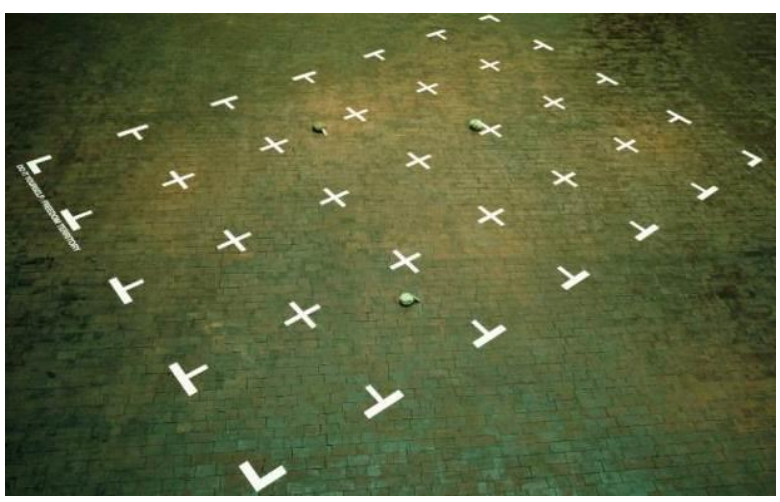

Antonio Dias, Do it yourself: Freedom Territory, 1969, instalação com fita adesiva, 600 x $400 \mathrm{~cm}$.

\footnotetext{
${ }^{13}$ Antonio DIAS, Do it yourself: Freedom Territory, 1969, instalação com fita adesiva, 600 x $400 \mathrm{~cm}$, col. Daros LatinAmerica, Zurique.

${ }^{14}$ Em inglês no original: "Do it yourself: Freedom Territory / a basic open structure, which only works from the moment someone uses the space declared free to put on an action, be it mental, physical or visual. It is important that the person adopts a complete nonconditioned stand before penetrating the territory-structure. No pre-established dimensions: to be made in any scale." Hélio OITICICA / Antonio DIAS, "Project-book - 10 plans for open projects", op.cit.
} 
Mas em Trama, de 1977, restarão apenas vestígios ou rastros desta proposição. As palavras estão diagramadas como se fizessem parte de um texto maior, que não existe mais:

DO IT YOURSELF FREEDOM TERRITORY

MONOBLOC - PLURIDEA

PENETRATING THE WHOLE WHICH CAME FIRST AND GENERATE IT'S

OWN PARTS

Trama adota a formulação da arte ambiental de Hélio Oiticica como modelo programático. Mas um programa impossível de ser seguido, pois a obra realiza o ambiental apenas graficamente - abstratamente - como modelo para a reflexão e crítica, mas não para a experiência dos sentidos.

\section{A linguagem serve para condenar os fatos}

Mediante a articulação descontínua da geometria e da participação, Trama não se propõe a satisfazer os sentidos ou à "invenção imediata do instante" como propunha Oiticica em 1966. Aqui, passado (a descrição analítica de um espaço) e futuro (o projeto para uma ação) estão reunidos num outro "instante" (não sensível). Proposições de ação futura $E$ descrições do espaço experimentado. Ao articular (não sem ironia) o espaço da arte ambiental de H.O. como "monumentos" impossíveis, Trama opera uma aglutinação de tempo histórico, contrapondo materiais do debate artístico brasileiro anterior.

$\mathrm{Na}$ contramão do processo de reconstituição estética da aura, que estava em curso na segunda metade dos anos 1970, Trama recolhe - como na imagem-idéia do trapeiro descrita por Benjamin - rastros, vestígios e fragmentos da história recente da arte no país. 
Benjamin: "Rastro e aura. (...) No rastro, apoderamo-nos da coisa; na aura, ela se apodera de nós." 15

No choque entre projeto totalizante e experiência do instante - apoderando-se da lembrança "tal como ela lampeja num instante de perigo"16 - a lição que é possível aprender(mos) com Trama é a da instauração, realizada a partir dos lapsos e descontinuidades entre imagens e palavras, de uma nova temporalidade, recheada das possibilidades daquele "tempo-de-agora" (Jetztzeit) - que não é senão o da rememoração.

Em Trama, encontramos aberta, talvez pela última vez na arte brasileira, a fresta daquela "porta estreita pela qual pode entrar o Messias". ${ }^{17}$

\footnotetext{
${ }^{15}$ Benjamin, Walter, Passagens. Org. da edição brasileira Willi Bolle. Trad. Irene Aron e Cleonice Mourão. Editora UFMG, Belo Horizonte, 2007, pág. 490.

${ }^{16}$ Benjamin, Walter, "Tese VI", Sobre o Conceito de História, apud Löwy, Michael, Walter Benjamin: Aviso de Incêndio - Uma leitura das teses "sobre o conceito de história", trad. Wanda Nogueira Caldeira Brant, trad. das teses Jeanne Marie Gagnebin e Marcos Lutz Muller, São Paulo, Boitempo Editorial, 2005, p. 65.

${ }^{17}$ Benjamin, Walter, "Apêndice B", Sobre o conceito de história, op. cit., p. 142.
} 